\title{
DISPOSITIVOS LEGAIS NO TRABALHO DE CUIDADORES: APLICAÇÃO EM INSTITUIÇÕES DE LONGA PERMANÊNCIA
}

\author{
Claudia Daiane Trentin Lampert* \\ trentin rs@yahoo.com.br \\ Silvana Alba Scortegagna** \\ silvanalba@upf.br \\ Denize Grzybovski** \\ gdenize@upf.br \\ *Faculdade Ideau \\ **Universidade de Passo Fundo
}

http://dx.doi.org/10.1590/1413-2311.09515.57137

Recebido em 16/07/2015

Aprovado em 29/05/2016

Disponibilizado em 31/01/2017

Avaliado pelo sistema "double blind review"

Revista Eletrônica de Administração

Editora-chefe: Aurora Zen

ISSN 1413-2311 (versão "on line")

Editada pela Escola de Administração da Universidade Federal do Rio Grande do Sul.

Periodicidade: Quadrimestral

Sistema requerido: Adobe Acrobat Reader

\section{RESUMO}

Em razão do aumento da longevidade da população, do incremento da demanda por cuidadores formais e da necessidade de amparar legalmente a profissão de cuidador no Brasil, questionam-se as competências requeridas do cuidador. $\mathrm{O}$ objetivo deste artigo científico foi investigar a aplicação dos dispositivos legais para o trabalho de cuidadores em Instituições de Longa Permanência (ILPIs). Participaram do estudo 10 cuidadores de ILPIs, do estado do Rio Grande do Sul, que responderam a um questionário do perfil sociodemográfico e da função de cuidar. Os resultados indicaram que a maior parte dos profissionais são mulheres, com idades, escolaridade e formação condizentes com os preceitos preconizados pelas legislações, ainda em discussão. Entre as principais funções desempenhadas, os cuidados com a higiene, a alimentação e a locomoção foram predominantes. A formação para o trabalho com idosos foi destacada como a principal competência necessária para atuação profissional. A aprovação e a aplicação dos dispositivos legais para cuidadores de idosos é uma ação urgente e necessária tanto como proteção do trabalhador quanto para qualificar os serviços prestados.

Palavras-chave: mercado de trabalho, profissão de cuidador, legislação, profissões inovadoras. 


\title{
LEGAL PROVISIONS ON THE WORK OF CAREGIVERS: APPLYING IN LONG-STAY INSTITUTIONS
}

\begin{abstract}
Due to the increase in population longevity, increased demand for formal caregivers and the need to legally protect the caregiver profession in Brazil, question themselves the skills required of the caregiver. The objective of this article was to investigate the application of legal provisions for working caregivers in long term care facilities (ILPIs), identifying the competencies (knowledge, skills and attitudes) caregiver. The study enrolled 10 caregivers from Rio Grande do Sul state, which answered a questionnaire regarding the sociodemographic profile and the function of care itself. Results indicated that the majority of professionals are women, with ages, education and training consistent with the precepts advocated by the legislation, which is still in discussion. Among the main functions performed, the care with hygiene, feeding and commute were predominant. Formal education for the work with the elderly was highlighted as the main competency necessary for professional placement. The approval and implementation of the legal provisions for elderly caregivers is an urgent and necessary action to be taken, and serves as a means of protecting the worker and to improve the quality of the services provided.
\end{abstract}

Key-words: job market, caregiver profession, legislation, innovative professions

DISPOSITIVOS LEGALES EN EL TRABAJO DE CUIDADORES: APLICACIÓN EN INSTITUCIONES DE LARGA DURACIÓN

\begin{abstract}
RESUMEN
Con el aumento de la longevidad de la población, el aumento de la demanda de cuidadores formales y la necesidad de amparar legalmente la profesión de cuidador en Brasil, se cuestionan las competencias necesarias del cuidador. El objetivo de este artículo científico fue investigar la aplicación de los dispositivos legales para el trabajo de cuidadores en Instituciones de Larga Duración (ILPIs). Participaron del estudio 10 cuidadores de ILPIs, del estado del Rio Grande do Sul, que contestaron a un cuestionario de perfil sociodemográfico y sobre la función de cuidar. Los resultados indicaron que la gran mayoría de los profesionales son mujeres, con edades, educación y formación de acuerdo a los preceptos recomendados por la legislación, aún en discusión. Entre las principales funciones desempeñadas, los cuidados con la higiene, la alimentación y la locomoción fueron predominantes. La formación para el trabajo con mayores fue destacada como la principal competencia necesaria para la actuación profesional. La aprobación y la aplicación de los dispositivos legales para cuidadores de mayores es una acción urgente y necesaria tanto como protección del trabajador cuanto para calificar los servicios ofrecidos.
\end{abstract}


Palabras-clave: sector de trabajo, profesión de cuidador, legislación, profesiones innovadoras.

\section{INTRODUÇÃO}

No Brasil, as discussões sobre a profissão do cuidador iniciaram-se efetivamente com a Política Nacional do Idoso, promulgada em 1994, seguida da primeira redação da Política Nacional de Saúde do Idoso, em 1999 (BATISTA; ALMEIDA; LANCMAN, 2014). A partir daí, o cuidador foi definido como uma pessoa, membro familiar ou não, com ou sem remuneração, que cuida do idoso doente ou dependente no exercício das atividades diárias, sendo excluídas de suas funções, técnicas e procedimentos pertinentes a outras profissões, especialmente da enfermagem (PORTARIA, nº1395/99).

Atualmente, a função de cuidador é reconhecida como uma ocupação pelo Ministério do Trabalho e Renda, por meio da inclusão na Classificação Brasileira de Ocupações (CBO, 2002). Sob o código 5162-10 (cuidador/acompanhante de idosos e/ou pessoas dependentes), o cuidador é definido como aquele que cuida a partir de objetivos estabelecidos por instituições especializadas ou responsáveis diretos, zelando pelo bem-estar, saúde, alimentação, higiene pessoal, educação, cultura, recreação e lazer da pessoa assistida.

Apesar da importância social da profissão, o trabalho do cuidador, os aspectos legais da profissão e o debate dos aspectos específicos da gestão de pessoas em Instituições de Longa Permanência para Idosos (ILPIs) não tem recebido a devida atenção dos pesquisadores brasileiros da área gestão de pessoas e relações de trabalho. $\mathrm{O}$ aumento da longevidade e o envelhecimento populacional são elementos do contexto que impulsionaram a busca por outras formas de moradia não familiares, por conseguinte a demanda pela profissão de cuidador. Assim, o objetivo deste artigo foi investigar a aplicação dos dispositivos legais para o trabalho de cuidadores em ILPIs, identificando as competências (conhecimentos, habilidades e atitudes) do cuidador.

As mudanças demográficas em todo o mundo confirmam o envelhecimento populacional como processo universal e os efeitos sobre diferentes facetas da vida humana como o sistema previdenciário, mercado de trabalho, modelos de atenção à saúde, condições de vida, e a necessidade de cuidados de longa duração de pessoas dependentes (SOTOS; PARDOS, 2010).

Segundo a Organização das Nações Unidas (ONU), o Japão é constituído por uma sociedade superidosa, pois os habitantes com 65 anos e mais já alcançam mais de $20 \%$ da REAd | Porto Alegre - Edição 85 - N 3 - Setembro / Dezembro 2016 - p. 360 - 380 
população total. Diante deste incremento populacional, desde a década de 1960 este país discute políticas sociais políticas sociais para o bem-estar dos idosos, com a introdução de um plano de atendimento denominado Seguro de Cuidados de Longa Duração (Long-Term Care Insurance), efetivado no ano de 2000. Este seguro operacionaliza e financia planos personalizados de cuidados, de acordo com necessidades específicas e o grau de dependência dos idosos segurados e, intermedia o contato dos idosos com os prestadores de cuidado em diferentes modalidades como cuidado domiciliar, centros de assistência dia, e as instituições de cuidados permanentes (GUIMARÃES; HIRATA; SUGITA, 2011).

Desse modo, as políticas públicas japonesas buscam definir e reconhecer o trabalho do cuidado, estipulando diferentes categorias de cuidadores, conforme carga horária dos cursos de formação. Contudo, ainda apresentam deficiências, principalmente no atendimento aos idosos que vivem sozinhos, com menos condições financeiras, e em medidas voltadas aos cuidadores familiares (GUIMARÃES; HIRATA; SUGITA, 2011).

Na Europa, em países em que o envelhecimento já está consolidado como Portugal e Espanha, há o incremento de estudos sobre os serviços de cuidados de longa duração. Tais estudos recaem sobre o funcionamento de casas de repouso e clínicas geriátricas, às necessidades de profissionais qualificados, às condições de mercado de trabalho dos cuidadores formais e o desenvolvimento de políticas públicas que atendam a demanda do contingente de idosos e de pessoas com dependência (CARDOSO et al., 2012; SOTOS; PARDO, 2010).

Nos Estados Unidos, Zarit e Reamy (2013) referem que o crescente envelhecimento da população implica na revisão dos papéis das pessoas e da estrutura das instituições que cuidam dos adultos mais velhos, bem como de quais são os serviços de assistência que precisam ser ofertados nos próximos dez anos para atender às necessidades da população com este perfil. Os autores chamam a atenção para o fato de que, mesmo com incentivos e programas de políticas públicas para a permanência do idoso no seu domicílio, há uma expansão dos serviços de lares de vida assistida; muitos idosos acabarão por ter cuidado institucional, aumentando a demanda por cuidadores formais.

No Brasil, a certeza do envelhecimento acelerado (KÜCHEMANN, 2012), acompanhada pela incerteza das condições de cuidados dos longevos (SILVA; FALCÃO, 2014), produz necessidades e demandas sociais que requerem políticas adequadas do Estado e da sociedade (CAMARANO; KANSO, 2010). Sendo assim, o debate transdisciplinar das 
questões que envolvem o mercado de trabalho e a gestão das organizações de longa permanência tem gerado vários posicionamentos.

A legislação brasileira preconiza que o cuidado ao idoso deve ser de responsabilidade de sua família (POLÍTICA NACIONAL DE SAÚDE DO IDOSO, 1999; ESTATUTO DO IDOSO, 2003). Porém, Camarano e Kanso (2010) referem que com a redução da fecundidade, a crescente participação da mulher no mercado de trabalho, e aumento da sobrevivência de pessoas com redução da capacidade física, cognitiva e mental, a possibilidade familiar de atender e zelar pelo idoso se tornou escasso, aumentando a necessidade de optar-se por outros locais de moradia e outras formas de cuidado não familiares.

É neste contexto que as ILPIs vêm se tornando um lugar privilegiado, na medida em que se caracterizam como uma residência coletiva, que atende tanto idosos independentes em situação de carência de renda e/ou de família quanto àqueles com dificuldades para o desempenho das Atividades da Vida Diária (AVD), que necessitem de cuidados prolongados. Em estudo censitário realizado em todo território nacional, os autores supramencionados apontaram que as ILPIs estão trabalhando em plena capacidade, com 91,6\% dos leitos ocupados, e um contingente de cerca de 100 mil residentes.

É consenso entre os pesquisadores que as ILPIs devem ser um ambiente provedor de bem-estar aos idosos, oferecendo amparo social e assistência integral em saúde aos seus residentes. Para tanto, a eficiência e qualidade dos serviços prestados devem estar relacionadas com a qualificação dos cuidadores e funcionários (GARBIN et al., 2010; RIBEIRO et al., 2008; VIEIRA et al., 2011), pois, as ações de cuidado estão na base do trabalho desenvolvido nas instituições em prol da promoção da qualidade de vida dos idosos (CASADEI; SILVA; JUSTO, 2011).

Com uma perspectiva analítica do marco legal da profissão de cuidador, desenvolveu-se um estudo exploratório descritivo com mulheres cuidadoras em duas ILPIs, no Estado do Rio Grande do Sul. Os resultados são expostos neste artigo, em três seções, além desta introdução. A primeira seção apresenta a regulação do trabalho de cuidador no contexto brasileiro. A segunda seção traz os procedimentos metodológicos adotados na investigação empírica. Na terceira seção são apresentados e analisados os dados da pesquisa, e, na sequência são apresentadas as considerações finais.

\section{O TRABALHO DE CUIDADOR NO CONTEXTO BRASILEIRO}


O perfil sociodemográfico brasileiro e mundial tem apresentado significativas mudanças em direção ao envelhecimento populacional (CAMARANO; KANSO, 2010; KÜCHEMANN, 2012; BRASIL, 2015). Projeções das Nações Unidas indicam que uma em cada nove pessoas no mundo tem 60 anos de idade e mais, e a expectativa é que em 2050, haja mais idosos que crianças menores de 15 anos de idade (BRASIL, 2015). De acordo com o Censo Demográfico 2010, divulgado pelo Instituto Brasileiro de Geografia e Estatística (IBGE), os idosos representam 23,5 milhões dos brasileiros, mais que o dobro do registrado em 1991, quando a faixa etária contabilizava 10,7 milhões de pessoas. Para o Estado do Rio Grande do Sul, a perspectiva é de que, em 2027 o um número de idosos ultrapasse o de crianças.

Nesse contingente, aumenta a demanda por profissionais capacitados para o cuidado de pessoas idosas e pelos serviços prestados pelas ILPIs, em substituição aos cuidados familiares prestados no domicílio do idoso (CAMARANO; KANSO, 2010; SILVA; FALCÃO, 2014). Primordialmente, o cuidado aos adultos mais velhos é atribuição da família, sendo uma tarefa conferida às mulheres, resultado de construções históricas e sociais, determinadas pela divisão sexual do trabalho, cabendo à mulher a organização da vida familiar.

Contudo, além do âmbito familiar, os cuidados formais e institucionais aos idosos também são, em sua maioria, prestados por mulheres (BAUER; STROKA, 2013; KÜCHEMANN, 2012; SILVA; FALCÃO, 2014). Guimarães, Hirata e Sugita (2011) afirmam que diante das tendências demográficas do processo de envelhecimento prolongado, a ação de cuidar, antes prestado majoritariamente pelas mulheres, passou a ser vista como um trabalho e profissão, sendo objeto de medidas políticas.

Para a CBO, o trabalho de cuidador pode ser desempenhado em domicílios ou instituições, sob alguma forma de supervisão. Quanto ao regime de trabalho, este pode ser autônomo ou assalariado, exercido em tempo integral ou por revezamento de turnos. A ocupação de cuidador é possível a pessoas maiores de 18 anos, com ensino fundamental completo, e formação em cursos e treinamentos profissionais com carga horária de 80/160 horas. Além do previsto pela CBO, a temática acerca dos cuidadores vem sendo apreciada em projetos de lei pela Câmara dos Deputados e Senado Federal, conforme descrito na Tabela 1, desde o ano de 2006.

Tabela 1.Projetos de Lei (PL) sobre a regulamentação do trabalho de cuidadores.

\begin{tabular}{lllll}
\hline $\begin{array}{l}\text { Projeto Ano } \\
\text { de Lei } \\
\text { (PL) }\end{array}$ & $\begin{array}{l}\text { Poder } \\
\text { Governamental }\end{array}$ & Proposição & Dispositivos/Princípios \\
\hline
\end{tabular}

REAd | Porto Alegre - Edição 85 - N 3 - Setembro / Dezembro 2016 - p. 360 - 380 


\begin{tabular}{|c|c|c|c|c|}
\hline $\begin{array}{l}\mathrm{PL} \\
\mathrm{n}^{\circ} 6966\end{array}$ & 2006 & $\begin{array}{l}\text { Câmara dos } \\
\text { Deputados }\end{array}$ & $\begin{array}{l}\text { Cria a profissão } \\
\text { de cuidador }\end{array}$ & $\begin{array}{l}\text { Caracteriza a profissão do cuidador, e o âmbito } \\
\text { domiciliar como o de atuação; } \\
\text { Indica os requisitos para o exercício da profissão; } \\
\text { Delega ao Ministério da Saúde o estabelecimento do } \\
\text { conteúdo programático dos cursos de formação. }\end{array}$ \\
\hline $\begin{array}{l}\mathrm{PL} \\
n^{\circ} 2880\end{array}$ & 2008 & $\begin{array}{l}\text { Câmara dos } \\
\text { Deputados }\end{array}$ & $\begin{array}{l}\text { Regulamenta a } \\
\text { Profissão de } \\
\text { Cuidador, } \\
\text { delimita o } \\
\text { âmbito de } \\
\text { atuação, fixa } \\
\text { remuneração } \\
\text { mínima e dá } \\
\text { outras } \\
\text { providências. }\end{array}$ & $\begin{array}{l}\text { Orienta quanto ao exercício da função no que se } \\
\text { refere à supervisão e a relação com outras profissões } \\
\text { da área da saúde, notadamente enfermagem e } \\
\text { medicina; } \\
\text { Reforça a aprovação em curso regular para } \\
\text { cuidadores, e dispõe que este deve ser promovido } \\
\text { por instituição de ensino superior ou instituição da } \\
\text { sociedade civil; } \\
\text { Institui o valor do piso nacional da categoria. }\end{array}$ \\
\hline $\begin{array}{l}\mathrm{PL} \\
\mathrm{n}^{\circ} 2178\end{array}$ & 2011 & $\begin{array}{l}\text { Câmara dos } \\
\text { Deputados }\end{array}$ & $\begin{array}{l}\text { Dispõe sobre o } \\
\text { exercício da } \\
\text { profissão } \\
\text { de Cuidador. }\end{array}$ & $\begin{array}{l}\text { Define o cuidador como profissional que atende aos } \\
\text { objetivos de instituições especializadas ou } \\
\text { responsáveis diretos pelo idoso; } \\
\text { Firma os requisitos de formação para o exercício da } \\
\text { profissão; } \\
\text { Cita as competências do cuidador, em relação à } \\
\text { pessoa cuidada. }\end{array}$ \\
\hline $\begin{array}{l}\text { PL } \\
n^{\circ} 539\end{array}$ & 2011 & $\begin{array}{l}\text { Câmara dos } \\
\text { Deputados }\end{array}$ & $\begin{array}{l}\text { Institui o dia } \\
\text { nacional do } \\
\text { cuidador de } \\
\text { idosos }\end{array}$ & $\begin{array}{l}\text { Institui } 20 \text { de março como o Dia Nacional do } \\
\text { Cuidador de Idosos; } \\
\text { Valoriza o papel do cuidador no desenvolvimento } \\
\text { afetivo, físico, cognitivo e sócio cultural dos idosos. }\end{array}$ \\
\hline $\begin{array}{l}\mathrm{PL} \\
\mathrm{n}^{\circ} 284\end{array}$ & 2011 & Senado Federal & $\begin{array}{l}\text { Dispõe sobre o } \\
\text { exercício da } \\
\text { profissão de } \\
\text { cuidador de } \\
\text { idoso. }\end{array}$ & $\begin{array}{l}\text { Determina o âmbito domiciliar e institucional como } \\
\text { o de atuação do cuidador de idosos e menciona as } \\
\text { funções a serem desempenhadas pelo profissional; } \\
\text { Firma os requisitos de formação para o exercício da } \\
\text { profissão; } \\
\text { Veda ao cuidador o desempenho de atividades de } \\
\text { outras profissões da saúde }\end{array}$ \\
\hline $\begin{array}{l}\mathrm{PL} \\
\mathrm{n}^{\circ} 4702\end{array}$ & 2012 & Senado Federal & $\begin{array}{l}\text { Dispõe sobre o } \\
\text { exercício da } \\
\text { profissão } \\
\text { de cuidador de } \\
\text { pessoa idosa e } \\
\text { dá outras } \\
\text { providências. }\end{array}$ & $\begin{array}{l}\text { Apensa o PL n }{ }^{\circ} 2178 / 2011 \text { e PL n }{ }^{\circ} 284 / 2011 \text {, } \\
\text { Define funções e amplia o âmbito de atuação dos } \\
\text { cuidadores; } \\
\text { Define critérios de idade e formação básicas } \\
\text { necessárias para o exercício da profissão; } \\
\text { Versa sobre a administração de medicamentos e } \\
\text { outros procedimentos de saúde realizados pelo } \\
\text { cuidador; } \\
\text { Aborda sobre as formas de contrato de trabalho do } \\
\text { cuidador; } \\
\text { Determina ao cuidador penas para crimes previstos } \\
\text { na Lei n }{ }^{\circ} 10.741 \text {, quando cometidos em exercício da } \\
\text { profissão. }\end{array}$ \\
\hline
\end{tabular}

Fonte: Elaborada pelas autoras.

No ano de 2006 que iniciou-se a discussão no Brasil sobre a legalidade do cuidador com o Projeto de Lei 6966. Este dispositivo propõe a criação da profissão, justificado pela REAd | Porto Alegre - Edição 85 - N 3 - Setembro / Dezembro 2016 - p. 360 - 380 
necessidade de um profissional habilitado para atuar na assistência de pessoas dependentes, devido a doenças ou à idade avançada, exceto tarefas e afazeres próprias dos profissionais de saúde. Delimita o serviço domiciliar e extra-institucional como o âmbito de sua atuação.

Na sequência, o PL 288/2008 propôs quanto à qualificação e a regulamentação do exercício profissional, estabelecendo parâmetros mínimos para a ação do cuidador. Este projeto gerou discussões importantes sobre a quem versa a responsabilidade quanto a formação e as atribuições do cuidador, tendo algumas proposições rejeitadas, e mantendo-se o PL 6966/2006 como suficiente e adequado.

Observa-se que em 2011, a temática dos cuidadores esteve na pauta das legislações propostas tanto pela Câmara de Deputados quanto do Senado Federal. Os PL 2178, 539 e 284 apontam os requisitos para o exercício da profissão com o estabelecimento de escolaridade mínima e formação em cursos para cuidadores, discutem sobre as atribuições, e ampliam o âmbito de atuação, estendendo a profissão de cuidador ao contexto institucional. A partir dessas construções, o PL 4702/2012, delimita quanto à profissão de cuidador de pessoa idosa, reunindo proposições já estabelecidas em outros projetos, sendo a legislação em tramite mais atual e que versa sobre diferentes aspectos da profissão.

Diante do exposto, a legislação brasileira propõe a alteração da função de cuidador de ocupação para profissão regulamentada. Os projetos de lei, ainda em trâmites, apresentam os requisitos, atribuições e questões trabalhistas da profissão. Batista, Almeida e Lancman (2014) afirmam que, apesar de algumas controvérsias entre os referidos projetos de lei, estes denotam o esforço do poder público na profissionalização dos cuidadores de idosos.

Por sua vez, os pesquisadores brasileiros no campo da gestão tem dado pouca atenção ao tema, sendo mais discutido nas ciências da saúde e no campo jurídico. A Administração é uma ciência social razão pela qual deveria voltar seu olhar para o fenômeno social “envelhecimento populacional”. Küchemann (2012) chama a atenção para o modelo inadequado preponderante no mercado de trabalho, que eleve as mulheres como únicas responsáveis pelo cuidado, evidenciando um debate que também contempla as questões de gênero, ou, como indicam os dados estatísticos apresentados pela Coordenação Geral dos Direitos do Idoso (BRASIL, 2015), a feminilização da velhice.

A maior parte dos estudos organizacionais brasileiros, no entanto, voltam-se às questões das gerações, aos desafios e estratégias na contratação de mão de obra nas organizações prestadoras de serviços tradicionais, à criação de valor na gestão da mão de obra, ao papel da força de trabalho na era do conhecimento e à rotação da mão de obra na indústria. As questões 
relativas às profissões inovadoras no mercado de trabalho no futuro, contexto no qual se insere a profissão de cuidador, são pouco debatidas.

O estudo de Neumark, Johnson e Mejia (2013) verificou projeções para 2018, sobre as demandas de força de trabalho e educacionais nos Estados Unidos. O estudo apontou para a mudança nas categorias de ocupações e demanda de mercado de trabalho, com o aumento de ocupações relacionadas aos cuidados com a saúde e ciência da computação, com maior taxa de crescimento nos empregos e a redução de ocupações agrícolas e de produção. Entende-se que as profissões relacionadas aos cuidados com as saúde abrangem a categoria dos cuidadores de pessoas idosas dependentes, tendo este trabalho a finalidade promover e manter a saúde destas pessoas.

Num dos poucos trabalhos nacionais sobre profissões do futuro, Wright, Silva e Spers (2010) identificaram que entre a crescente inovação, preocupação com o meio ambiente, busca por qualidade de vida e envelhecimento da população, os profissionais gerentes de ecorelações, chief innovation officers (CIO) e bioinformacionistas serão os mais demandados; curiosamente, a profissão de cuidador não aparece nos resultados, evidenciando uma lógica econômica no delineamento das profissões do futuro em detrimento do social presente nas atividades que envolvem o cuidado.

A atividade do cuidado à pessoas idosas ou dependentes funcionalmente, apresenta-se no escopo das profissões do futuro. Sua abrangência não se limita a atividade do indivíduo que exerce a função de cuidar, mas também ao empreendedor. Conforme Graevenitz, Harhoff e Weber (2010), o empreendedorismo é influenciado pelas intenções do indivíduo que por sua vez, estão intimamente interligadas com fatores exógenos. Neste sentido, a demanda de mercado emergente diante do envelhecimento, implicará na formação de novos gestores e empresários do cuidado em clínicas geriátricas, hospitais-dia, serviços de home-care privados, o que impele o desenvolvimento de legislações que amparem tanto o profissional quanto o gestor ou empregador na área de cuidados.

\section{METODOLOGIA}

Trata-se de um estudo descritivo exploratório, fruto de uma pesquisa mais ampla, realizado com 10 mulheres, cuidadoras formais de duas ILPI, uma filantrópica e outra privada, no estado do Rio Grande do Sul. Para tanto, utilizou-se um questionário do perfil sociodemográfico e da função de cuidador, desenvolvido pelas autoras deste estudo, com o 
objetivo de responder aos objetivos propostos. O instrumento foi composto por 12 questões fechadas sobre idade, escolaridade, situação conjugal, religião, etnia, renda mensal, problemas de saúde, tempo de atuação como cuidador, jornada de trabalho semanal, principais atividades desenvolvidas no cuidado, cursos de formação e, motivações/competências para a atividade de cuidador formal.

Após a obtenção da carta de autorização dos diretores das ILPIs e da aprovação do estudo pelo Comitê de Ética em Pesquisa de uma Universidade, sob o protocolo de número 169.507, foram expostos os objetivos e procedimentos do estudo a todos os 13 cuidadores das duas ILPIs. Os que aceitaram participar do estudo assinaram o Termo de Consentimento Livre e Esclarecido, e responderam ao questionário do perfil sociodemográfico e da função de cuidador nas dependências das ILPIs, em um tempo aproximado de 30 minutos. Os resultados foram analisados quantitativamente, por meio de frequência das respostas.

\section{RESULTADOS E DISCUSSÃO}

No Quadro 1 são apresentados os dados de comparação entre o perfil sociodemográfico das participantes (idade, escolaridade, formação, regime de trabalho, salário e atividades desempenhadas) e os dispositivos legais propostos pelas legislações brasileiras.

Quadro 1. Comparação do perfil sociodemográfico dos cuidadores e os dispositivos legais.

\begin{tabular}{|c|c|c|c|}
\hline Variáveis & $\begin{array}{l}\text { Cuidadoras } \\
(n=10)\end{array}$ & $\begin{array}{l}\text { Legislação/ } \\
\text { diretrizes }\end{array}$ & Proposições/requisitos \\
\hline Idade & $\begin{array}{l}\text { Entre } 32 \text { e } 61 \text { anos } \\
M=46,3 \text { anos } \\
(D P=9,5)\end{array}$ & $\begin{array}{l}\text { CBO (2002) } \\
\text { PL n }^{\circ} 4702 / 2012\end{array}$ & Idade mínima 18 anos \\
\hline Escolaridade & $\begin{array}{l}\text { Ensino Médio }(\mathrm{n}=4) \\
\text { Curso técnico em } \\
\text { Enfermagem }(\mathrm{n}=3) \\
\text { Ensino Fundamental } \\
\text { incompleto }(\mathrm{n}=2) \\
\begin{array}{l}\text { Ensino } \\
\text { completo }(\mathrm{n}=1)\end{array}\end{array}$ & $\begin{array}{l}\text { CBO (2002) } \\
\text { PL n }{ }^{\circ} 6966 / 2006 \\
\text { PL n }{ }^{\circ} 2178 / 2011 \\
\text { PL n }{ }^{\circ} 284 / 2011 \\
\text { PL n }{ }^{\circ} 4702 / 2012\end{array}$ & Ensino fundamental completo. \\
\hline $\begin{array}{l}\text { Formação em } \\
\text { curso de } \\
\text { cuidadores }\end{array}$ & $\begin{array}{l}\text { Curso concluído }(n=4) \\
\text { Em andamento }(n=2) \\
\text { Sem formação em curso de } \\
\text { cuidadores }(n=4)\end{array}$ & $\begin{array}{l}\text { CBO (2002) } \\
\text { PL n }{ }^{\circ} 6966 / 2006 \\
\text { PL n }{ }^{\circ} 2880 / 2008 \\
\text { PL n }{ }^{\circ} 2178 / 2011\end{array}$ & $\begin{array}{l}\text { Conclusão em Curso de qualificação } \\
\text { para formação de cuidadores para o } \\
\text { exercício da profissão. }\end{array}$ \\
\hline
\end{tabular}

REAd | Porto Alegre - Edição 85 - N 3 - Setembro / Dezembro 2016 - p. 360 - 380 


\begin{tabular}{|c|c|c|c|}
\hline & & $\begin{array}{l}\text { PL } \mathrm{n}^{\circ} 284 / 2011 \\
\mathrm{PL} \mathrm{n} \mathrm{n}^{\circ} 4702 / 2012\end{array}$ & \\
\hline $\begin{array}{l}\text { Regime de } \\
\text { trabalho }\end{array}$ & $\begin{array}{l}\text { Turnos de } 6 \text { horas diárias, } \\
\text { com plantões de } 12 \text { horas } \\
\text { em finais de semana }(\mathrm{n}=9) \\
\text { Jornada de } 40 \text { horas } \\
\text { semanais }(\mathrm{n}=1) \\
\text { Contrato por CLT }(\mathrm{n}=10)\end{array}$ & $\begin{array}{l}\text { CBO (2002) } \\
\text { PL n }^{\circ} 4702 / 2012\end{array}$ & $\begin{array}{l}\text { Turno integral ou por revezamento de } \\
\text { turnos; } \\
\text { Quando contratado por pessoa jurídica, } \\
\text { seguirá a Consolidação das Leis do } \\
\text { Trabalho }\end{array}$ \\
\hline Salário & $\begin{array}{l}\text { De } 1 \text { a } 2 \text { salários mínimos } \\
\text { regionais (Lei } 14460 / 2014) \\
(\mathrm{n}=9) \\
\text { Mais de } 2 \text { salários mínimos } \\
(\mathrm{n}=1)\end{array}$ & $\mathrm{PL} \mathrm{n}^{\circ} 2880 / 2008$ & $\begin{array}{l}\text { Valor de } 1 \text { (um) salário mínimo como } \\
\text { piso nacional da categoria }\end{array}$ \\
\hline $\begin{array}{l}\text { Atividades } \\
\text { desempenhadas }\end{array}$ & $\begin{array}{l}\text { Cuidados com a higiene } \\
\text { pessoal, alimentação e } \\
\text { auxílio na locomoção } \\
(\mathrm{n}=10) ; \\
\text { Administração }\end{array}$ & $\begin{array}{l}\text { CBO (2002) } \\
\text { PL n }{ }^{\circ} 2880 / 2008 \\
\text { PL n²178/2011 } \\
\text { PL n }{ }^{\circ} 284 / 2011 \\
\operatorname{PL~}^{\circ} 4702 / 2012\end{array}$ & $\begin{array}{l}\text { Zelar pelo bem-estar, saúde, } \\
\text { alimentação, higiene pessoal, educação, } \\
\text { cultura, recreação e lazer da pessoa } \\
\text { assistida; } \\
\text { Prestação de apoio emocional e na } \\
\text { convivência } \\
\text { social da pessoa idosa; } \\
\text { Cuidados de saúde preventivos, } \\
\text { administração } \\
\text { de medicamentos e outros } \\
\text { procedimentos de saúde; autorizados e } \\
\text { orientados por profissional de saúde; } \\
\text { Estimular a interação e comunicação } \\
\text { entre o idoso, seus familiares e a } \\
\text { comunidade. }\end{array}$ \\
\hline
\end{tabular}

Fonte: Elaborada pelas autoras

Quanto à idade, todas as cuidadoras tinham mais de 18 anos, atendendo aos critérios legais estabelecidos (CBO, 2002; PL 4702/2012). Conforme preconizado no PL 2178/2011, o cuidador, no cumprimento do seu trabalho, é responsável pelo idoso atendido, sendo previsto pelo PL 4702/2012 o aumento em 1/3 (um terço) na aplicação de penalidades para os cuidadores que cometerem crimes previstos na Lei $\mathrm{n}^{\circ} 10.741$ (ESTATUTO DO IDOSO, 2003) quando no exercício da profissão. Considerando a responsabilidade que advém do ato de cuidar, o cuidador deve dispor de condições de responder legalmente pelas suas condutas, por isso a maioridade legal.

Sobre a escolaridade, observa-se que maior parte das cuidadoras possuíam mais de 8 anos de estudo (n=8), contemplando os requisitos exigidos nos projetos de lei 6966/2006, 2178/2011, 284/2011 e 4702/2012 . Apenas duas cuidadoras possuíam ensino fundamental incompleto e estavam amparadas pela $\mathrm{CBO}$. No que diz respeito à formação e experiência, a CBO refere que o acesso ao emprego também pode ocorrer por meio de formação escolar mínima, da quarta série do ensino fundamental até o ensino médio, com curso ou treinamento REAd | Porto Alegre - Edição 85 - N 3 - Setembro / Dezembro 2016 - p. 360 - 380 
profissional básico. Deste modo, não estabelece critérios claros quanto à formação escolar exigida para atuação de cuidador. Em razão da importância da formação básica do cuidador, as legislações citadas postulam a conclusão no ensino fundamental como condição imprescindível para o ingresso na profissão.

A determinação do grau de instrução necessário para a atuação, fixado em lei, é uma medida para buscar a qualificação da profissão de cuidador. Soma-se a isto o fato de que os cuidadores com maior nível de escolaridade dispõem de mais recursos cognitivos para auxiliar os idosos nas AVD e, dessa forma, podem favorecer a manutenção da autonomia do idoso, qualificando as suas ações de cuidado (RIBEIRO et al., 2008; VIEIRA et al., 2011). Considerando que o cuidador em ILPI é aquele que realiza as ações primordiais à promoção e manutenção da saúde física e mental dos idosos, a maior escolaridade torna-se um dispositivo importante a ser observado, na medida em que adquire caráter de proteção à qualidade dos serviços prestados aos idosos.

Além de assegurar a maior eficiência e qualidade no serviço prestado ao idoso, o aumento do nível de escolaridade proporciona avanços para o profissional no mercado de trabalho. Conforme Neumark, Johnson e Mejia (2013) o incremento da escolaridade, e consequente melhorias na qualificação dos trabalhadores, pode auxiliar a manter e estimular a criação de empregos mais bem remunerados, trazendo inúmeros benefícios potenciais para os cidadãos e para a economia como um todo.

No que se refere à qualificação, observa-se que a maior parte das cuidadoras participantes deste estudo já havia concluído ou estava realizando o curso de cuidador de idosos, em instituições de ensino privadas, estando de acordo com o previsto nos projetos de lei. O PL 4702/2012, proposto pelo Senado Federal, apensa os PL 2178/2011 e PL 284/2011, e descreve de forma mais completa as proposições quanto à qualificação do profissional cuidador. Estabelece que está habilitado para o exercício desta profissão aquele que tiver concluído o curso de formação de cuidador de pessoa idosa. São dispensadas da exigência de conclusão de curso de formação as pessoas que estejam atuando na função há, no mínimo dois anos, quando a Lei entrar em vigor. Contudo, prevê que nos cinco anos seguintes o cuidador deverá realizar a referida formação ou concluir o programa de certificação de saberes reconhecido pelo Ministério da Educação.

Sobre o curso de formação, a referida legislação indica que este poderá ser de natureza presencial ou semipresencial, desde que conferido por instituição de ensino reconhecida por órgão público federal, estadual ou municipal competente. Estabelece que, no prazo de um ano 
a contar da vigência da lei, caberá ao órgão público regulamentar quanto à carga horária e conteúdos mínimos do curso de formação de cuidador e incentivar a formação do cuidador por meio das redes de ensino técnico-profissionalizante e superior.

Observa-se que a conclusão em curso de formação para cuidadores está incluída em cinco projetos de lei, mencionada como requisito para o exercício da profissão de cuidador. Conforme justificado no PL 2178/2011 é imprescindível à regulamentação da profissão de cuidador, o estabelecimento da importância da qualificação deste profissional para oferecer um atendimento que preserve a dignidade da pessoa cuidada.

Para Casadei, Silva e Justo (2011) o cuidador deve ter conhecimento das necessidades, possibilidades e limitações do idoso, dispondo de habilidades para dar conta de oferecer um cuidado integral e humanizado. Para tanto, os autores afirmam a preparação e formação do cuidador como um importante meio para a qualificação das suas ações de cuidado. Conforme Garbin et al. (2010), as pessoas que escolhem atuar como cuidador de idosos, principalmente no contexto institucional, estão sujeitos a ter que lidar com diferentes condições sociais, emocionais, físicas e afetivas apresentadas por eles, muitas vezes geradoras de desgaste físico e emocional para o cuidador. Deste modo, a formação pode subsidiar conhecimentos teóricos, humanos e éticos, que amparem a reflexão sobre suas ações e sentimentos, sendo um dispositivo também para o autocuidado do profissional.

Zarit e Reamy (2013) indicam que na prestação de serviços de cuidado profissional, a formação e treinamento são necessidades prementes, tanto no âmbito domiciliar quanto institucional. Além de enfatizar as tarefas de cuidados com a saúde, salientam que o treinamento de habilidades de comunicação entre os pacientes e cuidadores podem ser a chave para melhorar a aceitabilidade e eficácia dos serviços. Entretanto, segundo os autores, ainda há poucas pesquisas sobre o tipo de formação necessária e tipos de treinamentos que alcançam maiores resultados tanto para o ser cuidado quanto para o cuidador.

Os dispositivos legais descritos nas legislações visam assegurar o bem-estar dos idosos atendidos e também do cuidador. Consequentemente, a formação profissional do cuidador adquire relevância na qualificação das suas ações, cujas competências (conhecimentos, habilidades e atitudes) a serem desenvolvidas contemplam conhecimentos sobre o processo de envelhecimento da pessoa, habilidade em conceder/manter a autonomia do idoso e a atitude em direção à promoção do autocuidado.

Apesar das discussões sobre os cuidadores enfatizarem a importância da qualificação, ainda é precário o status dessa profissão no Brasil (GUIMARÃES; HIRATA; SUGITA, 
2011). Entre os motivos estão: a baixa qualificação exigida, falta de especialização e de formação profissional específica que identifique a profissão. É importante salientar os benefícios dirigidos ao idoso, por meio da regulamentação da profissão de cuidador, podem proporcionar mudanças positivas quanto à profissionalização e valorização deste trabalhador.

Em relação às questões trabalhistas, observa-se que todas as cuidadoras são contratadas por meio da CLT (Consolidação das Leis Trabalhistas), asseguradas pelos direitos e deveres que versam o regime celetista e de acordo com o preconizado no PL 4702/2012. Sobre o regime de trabalho e forma de contratação, a CBO apenas cita que o trabalho do cuidador pode ser autônomo ou assalariado e em horários variados.

Já o PL 4702/2012 define que a forma de contrato de trabalho pode ser de duas maneiras: (a) se contratado por pessoa física para seu próprio cuidado ou de seu familiar, seguirá a Lei $n^{\circ} 5.859 / 1972$, e legislação correlata; ou (b) se contratado por pessoa jurídica, entre elas as ILPIs, seguirá a CLT, Decreto-Lei n 5.452/1943 e legislação correspondente. Além de estabelecer a forma de contrato, este projeto de lei veda ao empregador exigir do cuidador a realização de outros serviços além daqueles voltados ao idoso, em especial serviços domésticos de natureza geral.

Os dispositivos da referida lei, visam regulamentar a contração do cuidador formal em organizações e domicílios. Além dessa possibilidade, Wright, Silva e Spers (2010) indicam que o envelhecimento populacional exigirá a criação de novos serviços de caráter personalizado e voltados para a qualidade de vida. Em vista disso, as atividades e prestação de serviços relacionados à demanda do envelhecimento, configuram-se como inovadoras e promissoras, e sendo alvo de novos estudos e discussões no âmbito das relações de trabalho. Estudos internacionais (CARDOSO et al., 2012; SOTOS; PARDO, 2010) apontam os serviços de cuidados de longa duração que incluem as atividades formais de cuidadores de idosos, os serviços prestados por ILPIs, e a integração com os serviços de saúde públicos, como um setor de serviços gerador de emprego, demandando articulações entre as políticas públicas e demandas de mercado que deem conta deste panorama.

Quanto à remuneração, a maior parte das cuidadoras do presente estudo $(n=9)$ recebiam até dois salários mínimos, referenciados no Rio Grande do Sul para empregados em entidades assistenciais, no valor de $\mathrm{R} \$ 943,98$, conforme Lei $\mathrm{N}^{\circ} 14460$ de 16/01/2014, vigente no ano de 2014. Não há piso salarial dos profissionais cuidadores, estabelecidos em termos de lei, nem um parâmetro que determine esses valores. 
Diante deste problema, o PL 2880/2008 propôs a definição de um piso salarial para a categoria dos cuidadoras, fixado em um salario mínimo, e corrigido anualmente pelo Índice Nacional de Preços ao Consumidor Amplo - IPCA. Contudo, em 2010, avaliação da Comissão de Trabalho, de Administração e Serviço Público, rejeitou esta proposição, retirando-a do PL 2880/2008. Os projetos de lei seguintes não abordaram a questão da remuneração salarial, porém, cabe lembrar que ainda estão em trâmites, aguardando apreciação em diferentes instâncias do governo federal. A maior escolaridade e formação acadêmica, a carga horária da jornada de trabalho com disponibilização de tempo parcial ou integral, e a demanda e oferta dos serviços são os principais determinantes do valor aferido à remuneração dos cuidadores formais de idosos, conforme indicam Bauer e Stroka (2013).

No tocante a funções desempenhadas, as cuidadoras referiram realizar os cuidados de higiene, alimentação e auxílio na locomoção dos idosos $(n=10)$, seguido de tarefas como administração de medicamentos, e outros procedimentos de saúde $(n=6)$ e de ações de apoio emocional e interação com os idosos $(n=5)$. Nota-se que as atividades voltadas para a promoção do autocuidado do idoso para o lazer, cultura e recreação foram menos citadas pelas cuidadoras, vislumbrando a necessidade de formação e consequente conhecimento sobre todas as atuações pertinentes no cuidado ao idoso, conforme será visto a seguir.

De acordo com o PL 4702/2012, que condensa as proposições do PL 2178/2011 e PL 284/2011, o cuidador de pessoa idosa é o profissional que desempenha funções de acompanhamento e assistência exclusivamente à pessoa idosa, tais como: prestação de apoio emocional e na convivência social; auxílio e acompanhamento na realização de rotinas de higiene pessoal, de nutrição, e locomoção; cuidados de saúde preventivos, administração de medicamentos e outros procedimentos de saúde; acompanhamento em atividades de educação, cultura, recreação e lazer. O PL 4702/2012 estabelece que as todas as funções desempenhadas pelo cuidador devem ser pautadas nos princípios e proteção dos direitos humanos, na ética, no respeito e na solidariedade, tendo como objetivo melhorias na qualidade de vida da pessoa idosa em relação a si, à sua família e à sociedade.

Além de definir as funções e atribuições do cuidador, a legislação pertinente busca delimitar o campo de atuação dos cuidadores, diferenciando as tarefas que são de competência das profissões de saúde regulamentadas, especialmente das ações específicas da área da enfermagem. Deste modo, em 2002 a CBO ressalva que a ocupação de cuidador não inclui o código 3222, que compreende técnicos e auxiliares de enfermagem. Na sequência, o PL 2880/2008, alerta que esse profissional, não poderá executar os serviços exclusivos de outras 
profissões da área de saúde legalmente regulamentadas, particularmente às da área da enfermagem e da medicina, sendo posteriormente, no PL 284/2011, vedado ao cuidador atividades de competência de outras profissões de saúde regulamentadas.

O PL seguinte, 4702/2012, veda ao cuidador de pessoa idosa, o desempenho de atividade que seja de competência de outras profissões legalmente regulamentadas, exceto se este for formalmente habilitado para o exercício de tais funções. Este projeto de lei indica como função dos cuidadores a administração de medicamentos e outros procedimentos de saúde, desde que autorizados e orientados por profissional de saúde habilitado responsável por sua prescrição. Contudo, não explicita quais seriam esses outros procedimentos de saúde cabíveis a ação do cuidador.

O Guia Prático do Cuidador, documento publicado pelo Ministério da Saúde (2008), cita alguns procedimentos técnicos que não devem ser executados por cuidadores, e que são de competência exclusiva dos profissionais de saúde, tais como aplicações de injeção no músculo ou na veia, curativos complexos, instalação de soro e colocação de sondas, etc. Este Guia estabelece que as atividades do cuidador devem ser planejadas junto aos profissionais de saúde. O PL 2880/2008 reafirma que o cuidador só poderá exercer sua função mediante orientações prescritas por profissionais de saúde responsáveis pelo tratamento e acompanhamento clínico do indivíduo sob sua responsabilidade. Visto as funções que devem ser desempenhadas pelos cuidadores, cabe reconhecer as características e competências necessárias para o exercício da profissão de cuidador de pessoa idosa (Figura 1).

Figura

\begin{tabular}{|c|c|c|c|}
\hline \multirow{6}{*}{ 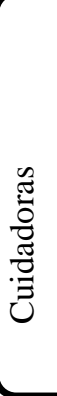 } & Competências/perfil pessoal elencados & \multirow{6}{*}{ 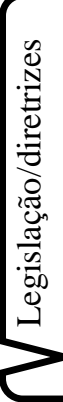 } & Competências/perfil pessoal elencados \\
\hline & $\begin{array}{l}\text { Formação para o trabalho com idosos } \\
(\mathrm{n}=7)\end{array}$ & & $\begin{array}{l}\text { Ter empatia, paciência, criatividade, } \\
\text { discrição, iniciativa e honestidade (CBO) }\end{array}$ \\
\hline & Capacidade de empatia $(n=4)$ & & Capacidade de acolhimento e escuta \\
\hline & Características pessoais $(n=3)$ & & $(\mathrm{CBO})$ \\
\hline & & & Demonstrar preparo emocional (CBO) \\
\hline & & & $\begin{array}{l}\text { Estar atento e ser solidário (PL } \\
2178 / 2011)\end{array}$ \\
\hline
\end{tabular}

Figura 1. Comparação das características/competências para a função de cuidador e os dispositivos legais propostos pelas legislações brasileiras.

Fonte: Elaborada pelas autoras

Conforme apresentado na Figura 1, o perfil e competências pessoais mais citados pelas cuidadoras diz respeito a formação para o trabalho com idosos $(n=7)$; capacidade de empatia 
$(\mathrm{n}=4)$, perceber as necessidades do idoso e; ter atributos, características pessoais como paciência e afetividade $(n=3)$. Estas competências elencadas pelas cuidadoras assemelham-se aos achados no estudo realizado por Silva e Falcão (2014) sobre as autoridades indispensáveis para o cuidado proferidas por cuidadoras formais em ILPIs, entendida como a associação de habilidades emocionais e instrumentais.

A formação para a atividade de cuidar de um indivíduo idoso, expressa pelas cuidadoras pode ser vista como um dispositivo para qualificar e amparar a ação do cuidador, exercendo um cuidado não apenas às questões relacionadas ao autoconservativo, mas ao cuidado integral, dirigido às relações interpessoais que se estabelecem, e a disposição pessoal para o envolvimento empático com o ser cuidado. Küchemann (2012) reforça a necessidade da disposição de competências pessoais no cuidado ao idoso, considerando que a ação de cuidar como profissão não pode estar pautada somente em questões humanitárias ou éticas, e sim no desenvolvimento de habilidades pertinentes a atuação.

Ressalta-se que a expressão dessas competências são permeadas por características pessoais, não podendo ser generalizadas a todas que atuam como cuidadoras (GARBIN et al., 2010). O perfil de personalidade daquele que busca atuar como cuidador deve ser considerado nos processos de seleção para a contratação de cuidadores em ILPIs. E, cabem as legislações, por meio de dispositivos, propor as competências pessoais básicas que devem ser observadas por aqueles que desejarem atuar como cuidadores.

A CBO cita que o cuidador deve possuir empatia, paciência, honestidade, iniciativa e preparo emocional. Considera como competência pessoal a capacidade de acolhimento e escuta, de tomar decisões, mantendo a calma em situações críticas, e buscar informações e orientações técnicas, reconhecendo limites pessoais.

O reconhecimento das competências pessoais necessárias ao cuidador torna-se importante para a qualificação do cuidador, interferindo no desenvolvimento de atitudes e competências práticas para a promoção de bem-estar ao idoso. Compreende-se que a formação, com a aquisição de conhecimentos e técnicas, é fundamental para o exercício da profissão de cuidador. Contudo, esta será mais resolutiva na prática do cuidador se contemplar os requisitos que observem as características de personalidade essenciais.

\section{CONSIDERAÇÕES FINAIS}


Ao atingir o objetivo de investigar a aplicação dos dispositivos legais no trabalho de cuidadores nas ILPIs, este estudo trouxe importantes contribuições. Os principais achados apontam que a maior parte das cuidadoras possuem os requisitos sociodemográficos (idade, escolaridade e formação escolarizada) para o exercício da profissão, conforme preconizado pelas legislações brasileiras, ainda em discussão. Observa-se que quanto às funções do cuidador, as AVD como higiene, alimentação e locomoção, destacam-se nas tarefas do cuidado ao idoso em ILPI. A formação para o trabalho ganha relevância entre as competências para a atuação profissional, sendo as ações de interação e apoio emocional aos idosos atribuições menos elencadas, e consideradas de menor importância no cuidado. Isso aponta para a necessidade de se destacar estas atribuições na qualificação da formação dos cuidadores.

Diante do exposto, destaca-se que a aprovação dos dispositivos legais e sua aplicação, configura-se em uma ação urgente e necessária para assegurar medidas de proteção aos direitos tanto dos profissionais quanto dos idosos assistidos. Ressalta-se que a aprovação do PL 4702/2012, contribuirá grandemente para a consolidação e valorização do cuidador enquanto categoria profissional, firmando direitos daqueles que já atuam na profissão, e esclarecendo aos futuros profissionais as relações de trabalho entre empregado e empregador. Além disso, cooperará para a qualificação dos serviços prestados no sentido de voltar-se para a manutenção da autonomia e da promoção de qualidade de vida do idoso institucionalizado.

Entre as contribuições deste trabalho destacam-se as seguintes: a) a necessidade da discussão sobre os desdobramentos da área de gestão de pessoas em novos cenários, dentre eles as organizações de ILPIs. O envelhecimento populacional é um fato inegável, e portanto, a profissão de cuidador ganha relevância, configurando-se como uma nova demanda de mercado de trabalho. Em vista disso, cabe a Administração, associada as demais ciências sociais e da saúde, versar sobre o mercado de trabalho contemporâneo, a luz de proposições e intervenções neste contexto; b) o desenvolvimento das seguintes competências no processo de formação dos cuidadores: conhecimentos teóricos sobre o processo de envelhecimento da pessoa humana, habilidade em conceder/manter a autonomia do idoso e atitude em direção à promoção do autocuidado.

Por fim, considerando ser estes resultados preliminares de um estudo mais amplo, apresenta-se como limitações a amostra restrita de participantes e o número reduzido de ILPIs. Consequentemente, futuras pesquisas poderiam avaliar o impacto da aplicação dos dispositivos legais da profissão do cuidador, a qualidade das ações desenvolvidas por este 
profissional e os benefícios proporcionados aos idosos, ampliando o número de organizações, abrangendo outros Estados, utilizando-se também de cuidadores de idosos de gênero masculino e de amostras mais representativas.

\section{REFERÊNCIAS}

BATISTA, M.P.P.; ALMEIDA, M.H.; LANCMAN, S. Cuidadores formais de idosos: contextualização histórica no cenário brasileiro. Revista Brasileira de Geriatria e Gerontologia, Rio de Janeiro, v. 17 n. 4, p. 879-885, 2014.

BAUER, T.K.; STROKA, M.A. Female labour supply and nursing home prices. Health Care Management Science, New York, v. 16, p. 258-270, 2013.

BRASIL. Lei $\mathrm{n}^{\circ} 10.741$, de 1 de outubro de 2003. Dispõe sobre o Estatuto do Idoso e dá outras providências. Diário Oficial da União. Brasília, DF. 2003.

BRASIL. Ministério da Saúde. Secretaria de Atenção à Saúde. Secretaria de Gestão do Trabalho e da Educação na Saúde. Série A. Normas e Manuais Técnicos. Guia Prático do Cuidador, Brasília. 2008. 65p.

BRASIL. Secretaria de Direitos Humanos. Dados sobre o envelhecimento no Brasil. Coordenação Geral dos Direitos do Idoso/Secretaria Nacional de Promoção Defesa dos Direitos Humanos, Brasília, [s/d]. Disponível em: <http://www.sdh.gov.br/assuntos/pessoaidosa/dados-estatisticos/DadossobreoenvelhecimentonoBrasil.pdf>. Acesso em: 30 abr. 2015.

BRASIL. Portaria no 1.395 de 10 de dezembro de 1999. Aprova a Política Nacional de Saúde do Idoso. Ministério da Saúde. Brasília, DF. 1999.

BRASIL. Portaria n ${ }^{\circ}$ 397, de 10 de dezembro de 2002. Institui a Classificação Brasileira de Ocupações. Ministério do Trabalho e Emprego. Brasília. 2002. Disponível em:

<http://www.mtecbo.gov.br>. Acesso em: 30 abr. 2015.

BRASIL. Projeto de Lei n ${ }^{\circ} 6.966$, de 2006. Cria a profissão de cuidador. Câmara dos Deputados. Brasília, DF. 2006.

BRASIL. Projeto de Lei no 2880. Regulamenta a profissão de cuidador de pessoa, delimita o âmbito de atuação, fixa remuneração mínima e dá outras providências. Câmara dos Deputados. Brasília, DF. 2008.

BRASIL. Projeto de Lei n ${ }^{\circ} 2178$, de 2011. Dispõe sobre o exercício da profissão de cuidador. Câmara dos Deputados. Brasília, DF. 2011.

BRASIL. Projeto de Lei n $^{\circ}$ 284, de 2011. Dispõe sobre o exercício da profissão de cuidador de idoso. Senado Federal. Brasília, DF. 2011.

BRASIL. Projeto de Lei n ${ }^{\circ} 539$, de 2011. Institui o dia nacional do cuidador de idosos. Câmara dos Deputados. Brasília, DF. 2011.

REAd | Porto Alegre - Edição 85 - № 3 - Setembro / Dezembro 2016 - p. 360 - 380 
BRASIL. Projeto de Lei ${ }^{\circ} 4702$, de 2012. Dispõe sobre o exercício da profissão de cuidador de pessoa idosa e dá outras providências. Senado Federal. Brasília, DF. 2012.

CAMARANO, A.A.; KANSO, S. As instituições de longa permanência para idosos no Brasil. Revista Brasileira de Estudos de População, Rio de Janeiro, v. 27, n. 1, p. 233-235, 2010.

CARDOSO, T. et al. Modeling the demand for long-term care services under uncertain information. Health Care Management Science, New York, v.15, n.4, p. 385-412, 2012.

CASADEI, M.C.; SILVA, A..C.; JUSTO, J.S. Bem-me-quer, malmequer: uma análise dos cuidados dispensados ao idoso asilar. Revista Kairós Gerontologia, São Paulo, v. 14, n. 6, p. 73-93, 2011.

GARBIN, C.A.S. et al. O envelhecimento na perspectiva do cuidador de idosos. Ciência \& Saúde Coletiva, Rio de Janeiro, v. 15, n. 6, p. 2941-2948, 2010.

GRAEVENITZ, G.; HARHOFF, A.; WEBER, R. The effects of entrepreneurship education. Journal of Economic Behavior \& Organization, Amsterdam, v. 76, n. 1, p. 90-112, 2010.

GUIMARÃES, N.A.; HIRATA, H. S.; SUGITA, K. Cuidado e cuidadoras: o trabalho de Care no Brasil, França e Japão. Revista Sociologia \& Antropologia, Rio de Janeiro, v. 1, n. 1, p. 151-180, 2011.

KÜCHEMANN, B. A. Envelhecimento populacional, cuidado e cidadania: velhos dilemas e novos desafios. Sociedade e Estado, Brasília, v. 27, n. 1, p. 165-180, 2012.

NEUMARK, D.; JOHNSON, H.; MEJIA, M. C. Future skill shortages in the U.S. economy? Economics of Education Review, Amsterdam, v. 32, p. 151-167, 2013.

RIBEIRO, M.T.F. et al. Perfil dos cuidadores de idosos nas instituições de longa permanência de Belo Horizonte, MG. Ciência \& Saúde Coletiva, Rio de Janeiro, v. 13, n. 4, p. 1285-1292, 2008 .

RIO GRANDE DO SUL. Lei ${ }^{\circ}$ 14460, de 16 de janeiro de 2014. Dispõe sobre o reajuste dos pisos salariais, no âmbito do Estado do Rio Grande do Sul para as categorias profissionais que menciona. Porto Alegre, Rio Grande do Sul. 2014.

SILVA, M.P.; FALCÃO, D.V.S. Cuidar de idosos numa ILPI na perspectiva de cuidadoras formais. Revista Kairós Gerontologia, São Paulo, v. 17, n. 3, p. 111-131, 2014.

SOTOS, F.E.; GARCIA, I.P. Long-term care, dependence and the third sector. Small Business Economics, New York, v. 38, p. 321-331, 2012.

VIEIRA, C.P.B. et al. Concepções de cuidado por cuidadores formais de pessoas idosas institucionalizadas. Revista Mineira de Enfermagem, Belo Horizonte, v. 15, n. 3, p. 348355, jan./mar. 2011.

ZARIT, S.H.; REAMY, A.M. Future Directions in Family and Professional Caregiving for the Elderly. Gerontology, Basel, v.59, p. 152-158, 2013.

REAd | Porto Alegre - Edição 85 - Nº 3 - Setembro / Dezembro 2016 - p. 360 - 380 
WRIGHT, J.T.C.; SILVA, A.T.B.; SPERS, R.G. O mercado de trabalho no futuro: uma discussão sobre profissões inovadoras, empreendedorismo e tendências para 2020. Revista de Administração e Inovação, São Paulo, v. 7, n. 3, p. 174-197, 2010. 